\title{
Ambulatory blood pressure in atrial fibrillation: an irregular conundrum of rate and rhythm
}

\author{
Dipak Kotecha and Gregory YH Lip \\ Hypertension Research (2013) 36, 854-855; doi:10.1038/hr.2013.59; published online 8 August 2013
}

$\mathrm{T}$ he variability of heart rate and stroke volume in patients with atrial fibrillation (AF) has engendered a scientific dilemma for blood pressure (BP) measurement. However from a clinical standpoint, ambulatory blood pressure measurement $(\mathrm{ABPM})$ provides a perfect solution; an average of BP (and hence the variability) across the 24 -h period. ABPM techniques avoid observer bias, can identify non-dippers and white-coat hypertension and also have proven prognostic implications in patients with sinus rhythm. ${ }^{1,2}$

Guidelines for the use of ABPM in those with AF remain understandably vague, principally due to the limited amount of published data. To our knowledge only four previous studies have explored ABPM vs. conventional measurement in patients with AF. Stewart et al. $^{3}$ analyzed four types of automated BP recorders sequentially, two of which were ABPM devices. In the 28 participants studied, BP measurement was successful in $80 \%$ (pooled for ABPM). Intrapatient variability was assessed by testing the two devices twice in each patient, with the standard deviation of the difference being 22 and $8 \mathrm{~mm} \mathrm{Hg}$ for systolic BP and 26 and $15 \mathrm{~mm} \mathrm{Hg}$ for diastolic BP. While not reaching statistical significance, variability was greater than demonstrated by conventional measurement. Almeida et al. ${ }^{4}$ assessed 30 AF patients and demonstrated a high percentage of successful recordings $(93 \%$ with $>80 \%$ valid recordings). The differences in 64 simultaneous measurements were 6 and $5 \mathrm{~mm} \mathrm{Hg}$ for systolic and diastolic BP respectively. Olsen et al. ${ }^{5}$ recruited patients with atrial arrhythmias and recorded ABPM

$\overline{\operatorname{Dr} \text { D Kotecha and Gregory YH Lip is at University of }}$ Birmingham Centre for Cardiovascular Sciences, City Hospital, Dudley Road, Birmingham B18 7QH, UK

E-mail: d.kotecha@bham.ac.uk pre- and post-cardioversion. In the group of 10 participants who remained in AF, systolic ABPM varied by $3-4 \%$ and diastolic ABPM by $1 \%$. In our own study of 23 outpatients with AF, the average proportion of valid ABPM readings during the $24-\mathrm{h}$ period was $81 \%$ (range $58-92 \%$ ). ${ }^{6}$ This is comparable to studies in sinus rhythm, with a $90 \%$ success rate (range 10-100\%). ${ }^{7}$ The correlation coefficients between manual and ABPM recordings were between 0.7 and 0.9 in our data, again similar to those published for patients in sinus rhythm. ${ }^{8}$

Stergiou et al. ${ }^{9}$ recently published a systematic review of automated vs. manual $\mathrm{BP}$ measurement in patients with $\mathrm{AF}$, including two of the ABPM studies already discussed. Their results were based on a total sample size of only 566 participants, comparing the use of automated (oscillometric or automated Korotkov) and sphygmomanometer (mercury or aneroid) BP measurement. Values for systolic BP were reasonably consistent, with a pooled correlation coefficient of 0.89 (95\% confidence interval (CI) 0.84-0.94) and automated methods giving values $0.5 \mathrm{~mm} \mathrm{Hg}$ higher than manual (95\% CI 0.9-1.9). However, diastolic BP measurement had a pooled correlation of 0.76 ( $95 \%$ CI $0.70-0.81$ ) with an average difference of $2.5 \mathrm{~mm} \mathrm{Hg}$ (95\% CI 0.6-5.7). The authors note that the latter contravenes the validation criteria for the US Association for the Advancement of Medical Instrumentation (AAMI). Heart rate, per se, did not appear to influence the accuracy of automated BP measurement.

In this issue of Hypertension Research, Giantin et al. ${ }^{10}$ have now added further data to support the notion that ABPM is feasible in AF patients. In a cross-sectional analysis, 100 hospitalized patients with AF were age- and gender-matched to patients with sinus rhythm. The AF group, similar to the other studies discussed had a 'stable' heart rate, persistent $\mathrm{AF}$ and were elderly (mean age 82 years). Valid ABPM was recorded in over $93 \%$ in both groups. The authors document that the values from ABPM and conventional sphygmomanometry were similar in those with sinus rhythm or AF. However, the real question relates to reproducibility and repeatability of ABPM in patients with AF. While the study does confirm that in both $\mathrm{AF}$ and sinus patients ABPM results for systolic and diastolic BP are lower than conventional assessment, the authors did not compare repeated measures and have therefore confirmed feasibility but not demonstrated clinical utility of ABPM in those with AF. Conversely, one could argue that as ABPM and sphygmomanometry provided identical pulse pressure data, the latter is preferable due to the ease of use and lower cost.

Additional issues that could affect the application of ABPM are the stability (and definition of stability) of heart rate in AF. Giantin et al. ${ }^{10}$ recruited those with a heart rate of 60-100 b.p.m., however many patients have intermittent changes in heart rate related to medication usage and activity, or have paroxysmal AF. Further, although there is now robust evidence for ABPM in patients with sinus rhythm affecting prognosis (and therefore management of hypertension), the same cannot be said about those with AF. Additional outcome data are required to validate clinical use of ABPM and confirm that the diastolic variability identified does not adversely affect the stratification of hypertension risk in AF patients. With the age- and sex-adjusted prevalence of $\mathrm{AF}$ increasing as well as global AF-related hospitalizations, accurately attributing risk to individuals with $\mathrm{AF}$ and hypertension is 
paramount as part of the holistic management of this arrhythmia, ${ }^{11}$ to prevent avoidable and devastating complications such as stroke and heart failure. With the available limited evidence, further study of $\mathrm{ABPM}$ in $\mathrm{AF}$ is clearly warranted.

1 Staessen JA, Thijs L, Fagard R, O'Brien ET, Clement D, de Leeuw PW, Mancia G, Nachev C, Palatini P, Parati G, Tuomilehto J, Webster J. Predicting cardiovascular risk using conventional vs ambulatory blood pressure in older patients with systolic hypertension. Systolic Hypertension in Europe Trial Investigators. JAMA 1999; 282: 539-546.

2 Verdecchia P, Porcellati C, Schillaci G, Borgioni C, Ciucci A, Battistelli M, Guerrieri M, Gatteschi C Zampi I, Santucci A, Santucci C, Reboldi G. Ambulatory blood pressure. An independent predictor of prognosis in essential hypertension. Hypertension 1994; 24: 793-801.

3 Stewart MJ, Gough K, Padfield PL. The accuracy of automated blood pressure measuring devices in patients with controlled atrial fibrillation. J Hypertens 1995; 13: 297-300.

4 Almeida L, Amado P, Vasconcelos N, Santos I, Alves J, Teles J, Nazaré J, Carmona J. [Is ambulatory blood pressure monitoring reliable in hypertensive patients with atrial fibrillation?]. Rev Port Cardiol 2001; 20 647-650.

5 Olsen R, Amlie A, Omvik P. Twenty-four-hour ambulatory blood pressure monitoring in atrial fibrillation. Blood Press Monit 2002; 7: 149-156.

6 Lip GY, Zarifis J, Beevers M, Beevers DG. Ambulatory blood pressure monitoring in atrial fibrillation. $A m ~ J$ Cardiol 1996; 78: 350-353.

7 Fravel MA, Ernst ME, Weber CA, Dawson JD, Carter BL, Bergus GR. Influence of patient characteristics on success of ambulatory blood pressure monitoring. Pharmacotherapy 2008; 28: 1341-1347.

8 Pearce KA, Grimm RH Jr, Rao S, Svendsen K Liebson PR, Neaton JD, Ensrud K. Population-derived comparisons of ambulatory and office blood pressures. Implications for the determination of usual blood pressure and the concept of white coat hypertension. Arch Int Med 1992; 152: 750-756.

9 Stergiou GS, Kollias A, Destounis A, Tzamouranis D. Automated blood pressure measurement in atria fibrillation: a systematic review and meta-analysis. J Hypertens 2012; 30: 2074-2082.

10 Giantin V, Perissinotto E, Franchin A, Baccaglini K, Attanasio F, Maselli M, Grosso G, Corradin ML, Tramontano A, Manzato E. Ambulatory blood pressure monitoring in elderly patients with chronic atrial fibrillation: is it absolutely contraindicated or a useful tool in clinical practice and research? Hypertens Res 2013; 36: 889-894.

11 Kirchhof P, Lip GY, Van Gelder IC, Bax J, Hylek E, Kääb S, Schotten U, Wegscheider K, Boriani G, Ezekowitz M, Diener $H$, Heidbuchel $H$, Lane $D$, Mont L, Willems S, Dorian P, Vardas P, Breithardt G, Camm AJ. Comprehensive risk reduction in patients with atrial fibrillation: emerging diagnostic and therapeutic options. Executive summary of the report from the 3rd AFNET/EHRA consensus conference. Thromb Haemost 2011; 106: 1012-1019. 